\title{
COMPARISON OF THE EFFICACY OF SODIUM BICARBONATE AND LIGNOCAINE ON REDUCING PAIN OF ROCURONIUM INJECTION IN PATIENTS UNDERGOING GENERAL ANAESTHESIA
}

\author{
Jayakumar Christudas 1 , Satheedevi Parameswaran'2, Nimitha ${ }^{3}$ \\ ${ }^{1}$ Additional Professor, Department of Anaesthesiology, Government Medical College, Manjeri, Malappuram, Kerala. \\ ${ }^{2}$ Associate Professor, Department of Anaesthesiology, Government Medical College, Manjeri, Malappuram, Kerala. \\ ${ }^{3}$ Senior Resident, Department of Anaesthesiology, GMCH, Trivandrum.
}

\begin{abstract}
BACKGROUND

Neuro muscular blocking agents have been an essential part of anaesthesia for more than 50 years and commonly used for tracheal intubation and intra operative relaxation. Neuro muscular blockers can be classified as depolarizing agents e.g. Succinyl choline and non-depolarizing agents. Rocuronium a newer amino steroidal muscle relaxant with a rapid onset and intermediate duration of action can be used as an alternative to succinyl choline for intubation.(1) Pain during intravenous injection is the most commonly reported side effect of rocuronium Numerous techniques have been used to reduce the incidence and intensity of this pain. The se include diluting rocuronium, administering it as an infusion rather than as a bolus injection and the use of other medications like lignocaine, antiemetics, antihistaminics, short acting opioids, sodium bicarbonate, ketamine, dexmedetomidine and esmolol.
\end{abstract}

\section{MATERIALS AND METHODS}

The study was conducted after obtaining approval of Research methodology and Human Ethical Committee of Government Medical College Trivandrum. Study population includes 120 adult patients of 18-60 years of age and of body weight 50-55 kg of ASA PS 1 \& 2 posted for elective general surgery under general anaesthesia. Patients were divided into two equal groups of 60 each according to the order they come for surgery. Group A receives $0.5 \mathrm{ml}$ of $7.5 \%$ sodium bicarbonate mixed with Inj. Rocuronium (50 mg). Group B receives $40 \mathrm{mg}$ lignocaine mixed with Inj. Rocuronium $(50 \mathrm{mg}$ ). Two intravenous lines with $18 \mathrm{G}$ IV cannula (One on the non-dominant hand and other on the dominant hand) were inserted and lactated ringers solution was infused at the rate of 100 $\mathrm{ml} / \mathrm{hr}$. After pre-oxygenation, a sleeping dose of IV thiopentone is given in the nondominant hand and once the consciousness is lost, the study drug (Freshly prepared) was injected over a period of $10 \mathrm{sec}$. in the dominant hand and patient was assessed for pain using the 4 point scale of limb withdrawal response. The heart rate and blood pressure response was also noted. Then 1.5 $\mathrm{mg} / \mathrm{kg}$ preservative free lignocaine is given to both study groups followed by induction dose of Propofol $2.5 \mathrm{mg} / \mathrm{kg}$ and waited for 90 seconds. The ease of intubation was noted for both the study groups. Anaesthesia was maintained with nitrous oxide and oxygen (4:2), Inj. Fentanyl $2 \mu \mathrm{g} / \mathrm{kg}$, Inj. Paracetamol $20 \mathrm{mg} / \mathrm{kg}$ IV and Inj. Propofol $75 \mu \mathrm{g} / \mathrm{kg} / \mathrm{min}$ iv. The duration of action of Rocuronium was noted in both the studies by noting the time in minutes at which the patient comes out of the relaxant. Heart rate, the duration of action of Rocuronium was noted in both the studies by noting the time in minutes at which the patient comes out of the relaxant. Heart rate, systolic and diastolic blood pressure were recorded before the injection of the study drug, at the time of injection of the study drug, $1 \mathrm{~min}$ and $3 \mathrm{~min}$ after intubation. Within 24 hours after the operation, the injection site was checked for pain, oedema, wheal and flare response by an anaesthetist who was unaware of which drug was injected. Data was analysed using suitable software and appropriate statistical tools and expressed in frequency and percentages.

\section{RESULTS}

Pain response to a loading dose of rocuronium bromide was significantly low in group A as compared to group B. The incidence of mild pain associated with limb withdrawal movement at the wrist only was $20 \%$ in group B and only $8.3 \%$ in group A. The incidence of moderate pain associated with withdrawal of arm was $16.7 \%$ and no patients experienced severe pain associated with generalized response in group B. None experienced moderate or severe pain in group A. There was no significant difference in heart rates between the two groups at baseline and during injection of the drug but a significant difference was noted at 1 minute of intubation which was absent at the end of 3 minutes after intubation. There was a significant difference in the systolic blood pressure during drug injection, probably due to pain associated with injection of drug in group B while the systolic blood pressure at baseline, 1 minute and 3 minutes after intubation showed no significant difference. None of the patients in either group developed limb movement during laryngoscopy. None of the patients in either groups developed adverse effects in the form of oedema, wheal, pain and flare response within 24 hours at the site of injection.

\section{CONCLUSION}

After analysing the results of the present study, we find that injection of neutralized rocuronium is more efficacious than lignocaine in reducing the pain and withdrawal movements associated with the injection of rocuronium bromide.

\section{KEYWORDS}

Rocuronium, Lignocaine, 7.5\% Sodium Bicarbonate, Propofol, Endotracheal Intubation etc.

HOW TO CITE THIS ARTICLE: Christudas J, Parameswaran S, Nimitha. Comparison of the efficacy of sodium bicarbonate and lignocaine on reducing pain of rocuronium injection in patients undergoing general anaesthesia. J. Evolution Med. Dent. Sci. 2017;6(4):301-307, DOI: $10.14260 / \mathrm{Jemds} / 2017 / 68$ 
Financial or Other, Competing Interest: None.

Submission 07-12-2016, Peer Review 30-12-2016,

Acceptance 06-01-2017, Published 12-01-2017.

Corresponding Author:

Dr. Satheedevi $P$,

Additional Professor, Department of Anaesthesiology,

Government Medical College, Manjeri, Malappuram-676121.

E-mail: drsathee171@gmail.com

DOI: $10.14260 /$ jemds $/ 2017 / 68$

\section{(c) $(1) \ominus$}

\section{BACKGROUND}

Neuro muscular blocking agents have been an essential part of anaesthesia for more than 50 years and commonly used for tracheal intubation and intra operative relaxation. The use of neuro muscular blocking drugs in anaesthesia has its origin in South American Indians' arrow poisons or curare. Several nondepolarising neuro muscular blockers are still purified from naturally occurring sources. The agents pancuronium, vecuronium, rocuronium, atracurium, cisatracurium, doxacurium, mivacurium are entirely synthetic.

The neuro muscular blockers can be classified as depolarizing agents e.g. Succinyl choline and nondepolarizing agents. The non-depolarizing agents are further classified according to chemical class (Steroidal, benzylisoquinolinium, or other compounds). Nondepolarizing agents are also classified according to onset or duration of action (Long, intermediate and short acting).

Rocuronium (ORG9426), a newer amino steroidal muscle relaxant with a rapid onset and intermediate duration of action can be used as an alternative to succinyl choline for intubation.(2) This is to avoid the undesirable effects of succinyl choline like increase in intraocular pressure, intragastric pressure, intra cranial pressure, fasciculations, postoperative myalgia and hyperkalemia.(3)

Pain during intravenous injection is the most commonly reported side effect of rocuronium. Even after induction of anaesthesia, rocuronium causes hand or limb withdrawal in $85 \%$ of patients suggesting the presence of intense nociception. These withdrawal movements may negatively affect the patient outcome. The mechanism of rocuronium induced pain remains unclear although various theories have been proposed to explain the aetiology of this pain.). Peripheral veins are innervated with polymodal nociceptors which mediate the response to the injection of certain anaesthetics that cause pain.(4) Acidic and alkaline solutions elicit pain at $\mathrm{pH}$ less than 4 and more than 11 respectively. Rocuronium is supplied as an isotonic solution with $\mathrm{pH}$ of 4 . Direct activation of C-nociceptors by the osmolality or $\mathrm{pH}$ of the solution or activation by the release of endogenous mediators such as histamine, kinin and other substances mediating inflammation.

Numerous techniques have been used to reduce the incidence and intensity of this pain. These include diluting rocuronium, administering it as an infusion rather than as a bolus injection and the use of other medications like lignocaine(5) antiemetics,(6) antihistaminics,(7) short acting opioids(8) sodium bicarbonate,(9) ketamine,(10) dexmedetomidine,(11) and esmolol.

\section{Aim of Study}

To compare the efficacy of sodium bicarbonate and lignocaine on reducing pain of rocuronium injection in patients undergoing general anaesthesia.

\section{Objectives \\ Primary}

To compare pain as measured by 4 point scale of limb withdrawal movement during injection of intubating dose of rocuronium after neutralizing by addition of $0.5 \mathrm{ml}$ of $7.5 \%$ sodium bicarbonate and $40 \mathrm{mg}$ lignocaine in ASA 1 \& 2 patients aged 18-60 years and $50-55 \mathrm{~kg}$ body weight undergoing general anaesthesia for elective surgery

\section{Secondary}

1. To compare intubating conditions with either group

2. To compare the haemodynamic response to orotracheal intubation following the intubating dose of rocuronium.

3. To compare the duration of action of intubating dose of rocuronium

4. To check with $24 \mathrm{hrs}$, the adverse effects at the injection site such as pain, swelling, wheal, flare response.

\section{MATERIALS AND METHODS}

The study was conducted after obtaining approval of Research methodology and Human Ethical Committee of Government Medical College. Study population includes 120 adult patients of 18-60 years of age and of body weight 50-55 kg of ASA PS 1 \& 2 posted for elective general surgery under general anaesthesia. Patients were divided into two equal groups of 60 each according to the order they come for surgery. Group A receives $0.5 \mathrm{ml}$ of $7.5 \%$ sodium bicarbonate mixed with Inj Rocuronium (50 mg). Group B receives $40 \mathrm{mg}$ lignocaine mixed with Inj Rocuronium (50 mg). All the patients included in the study were subjected to a detailed pre-anaesthetic checkup. Age and weight were recorded and detailed informed consent obtained. The patients were fasted for 8 hours and premedication with oral Alprazolam $0.5 \mathrm{mg}$ and ranitidine $150 \mathrm{mg}$ given at $10 \mathrm{pm}$ on the day before surgery and at 6 am on the day of surgery. None of the patients were premedicated in the operation theatre. All emergency medicines were kept ready, anaesthesia machine check done and drugs to be studied were loaded in $10 \mathrm{ml}$ syringe and labelled A \& B. Standard monitors (ECG, Noninvasive blood pressure, pulse oximeter, finger on pulse) were attached and base line values were obtained. Systolic and diastolic blood pressure were recorded before the injection of the study drug, at the time of injection, 1 min and 3 min after intubation. Within 24 hours after the operation, the injection site was checked for pain, oedema, wheal and flare response by an anaesthetist who was unaware of which drug was injected. Two intravenous lines with $18 \mathrm{G}$ iv cannula (One on the non-dominant hand and other on the dominant hand) were inserted and lactated ringers solution was infused at the rate of $100 \mathrm{ml} / \mathrm{hr}$. After pre-oxygenation, a sleeping dose of iv thiopentone is given in the non-dominant hand and once the consciousness is lost, the study drug (Freshly prepared) was injected over a period of $10 \mathrm{sec}$ in the dominant hand and patient was assessed for pain using the 4 point scale of limb withdrawal response. The heart rate and blood pressure response was also noted. Then $1.5 \mathrm{mg} / \mathrm{kg}$ preservative free lignocaine is given to both study groups followed by induction dose of Propofol $2.5 \mathrm{mg} / \mathrm{kg}$ and waited for 90 seconds. The ease of intubation was noted for both the study groups. Anaesthesia was maintained with nitrous oxide and oxygen (4:2), Inj. Fentanyl $2 \mu \mathrm{g} / \mathrm{kg}$, Inj. Paracetamol 20 $\mathrm{mg} / \mathrm{kg}$ IV and Inj. Propofol $75 \mu \mathrm{g} / \mathrm{kg} / \mathrm{min}$ iv. The duration of 
action of Rocuronium was noted in both the studies by noting the time in minutes at which the patient comes out of the relaxant. Heart rate,

\section{Inclusion Criteria}

a. ASA PS $1 \& 2$.

b. Age group 18-60 years.

c. Weight 50-55 kg.

d. Elective general surgery under general anaesthesia.

\section{Exclusion Criteria}

a. Patient refusal.

b. Patients with chronic pain.

c. Patients undergoing emergency surgery.

d. Patients with history of drug allergy.

e. Patients with infection on the dorsum of hand.

f. Patients with anticipated difficult airway.

g. Patients receiving analgesics or sedatives.

Sample size calculated using the formula,

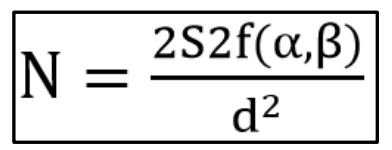

Where d- clinically significant difference; S- standard deviation; N- Sample size

With an error of $5 \%$, the sample size required for the study was calculated as 113 and a total rounded off to 120 patients comprising of 60 patients per group.

\section{RESULTS}

The observations made were tabulated and analysed using appropriate statistical tools. There was no significant difference in the base line variables or patient characteristics among the patients in both groups (Group A - Rocuronium + Sodium bicarbonate and group B- Rocuronium + Lignocaine).

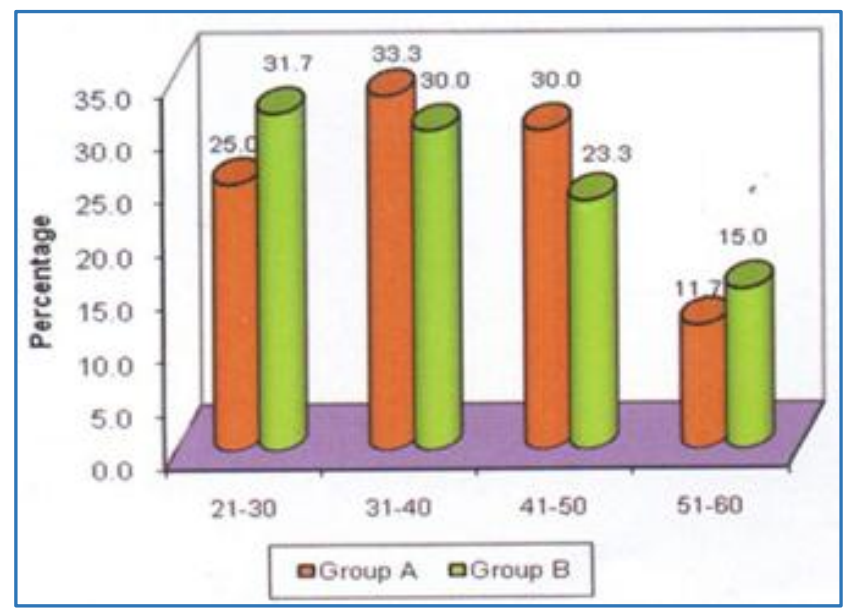

Figure i. Distribution of patients according to age

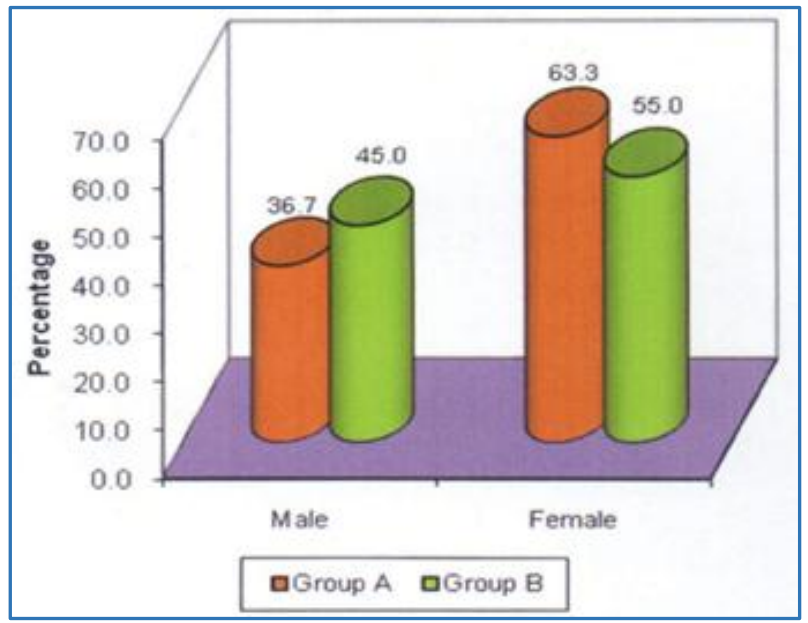

Figure ii. Distribution of patients according to gender

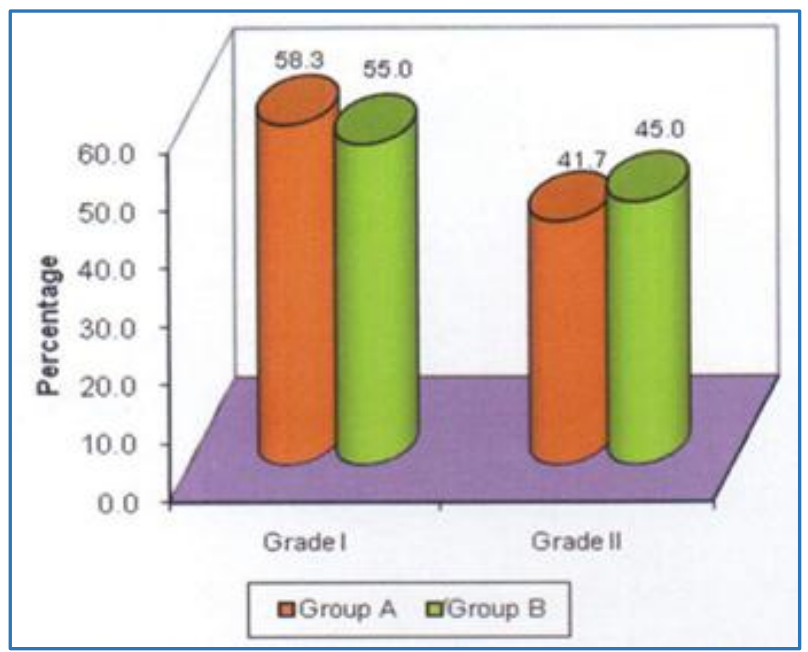

Figure iii Distribution of patients according to ASA

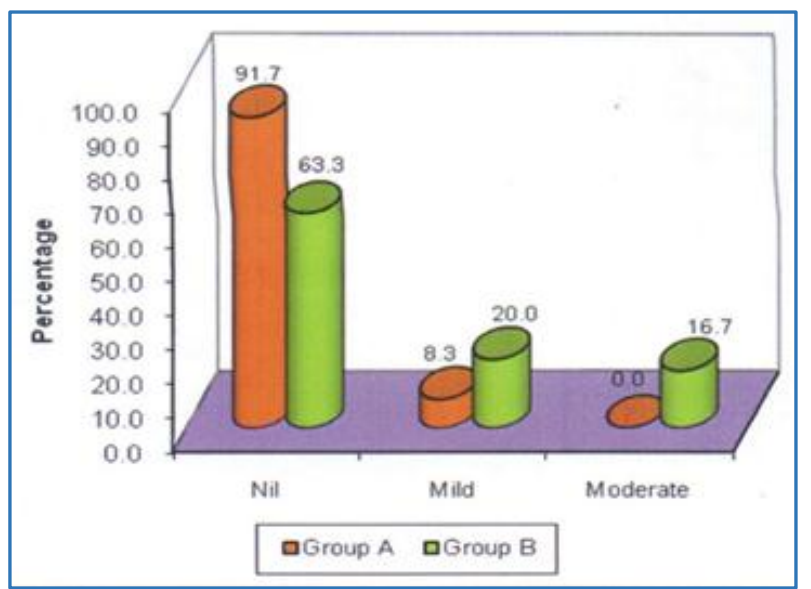

Figure iv. Distribution of patients according to pain

Pain response to a loading dose of rocuronium bromide was significantly low in group A as compared to group B. The incidence of mild pain associated with limb withdrawal movement at the wrist only was $20 \%$ in group B and only $8.3 \%$ in group A. The incidence of moderate pain associated with withdrawal of arm was $16.7 \%$ and no patients experienced severe pain associated with generalized response in group B. None experienced moderate or severe pain in group $A$. 


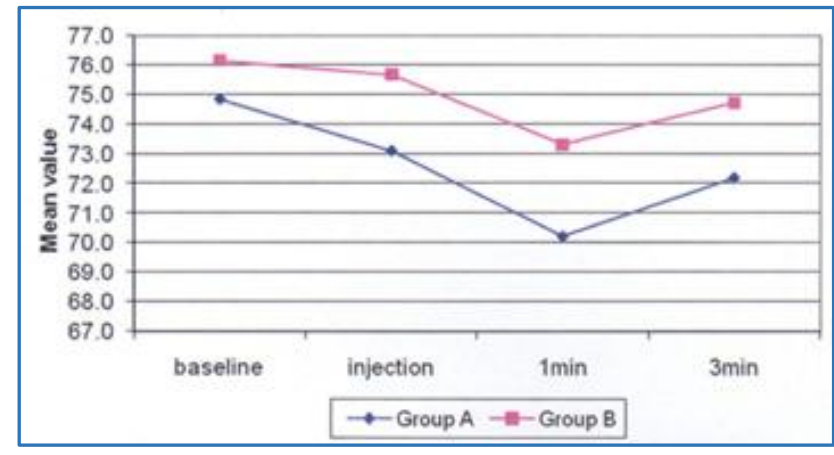

Figure v. Comparison of HR at different time interval based on group

There was no significant difference in heart rates between the two groups at baseline and during injection of the drug but a significant difference was noted at 1 minute of intubation which was absent at the end of 3 minutes after intubation.

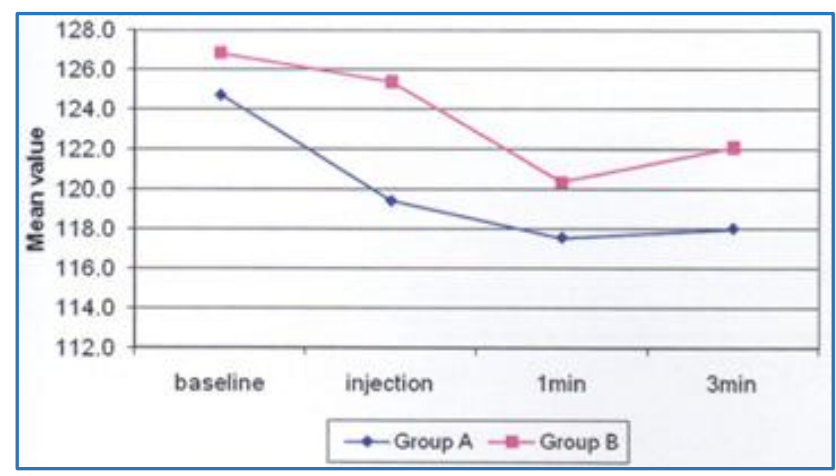

Figure vi. Comparison of SBP at different time interval based on group

There was a significant difference in the systolic blood pressure during drug injection, probably due to pain associated with injection of drug in group B while the systolic blood pressure at baseline, 1 minute and 3 minutes after intubation showed no significant difference.

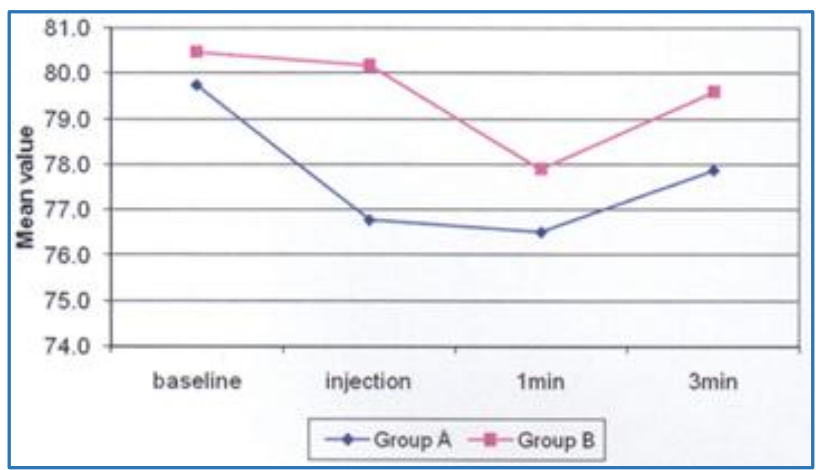

Figure vii. Comparison of DBP at different time interval based on group

There was no significant difference in Diastolic blood pressure between the groups at baseline, during drug injection, 1 minute and 3 minutes after intubation between the groups.

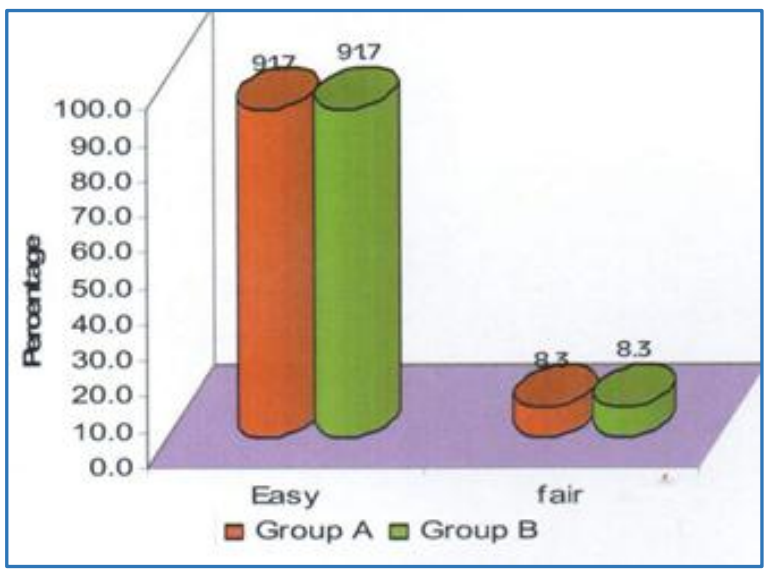

Figure viii. Comparison of sample based on laryngoscopy

Ease of laryngoscopy was comparable in both groups.

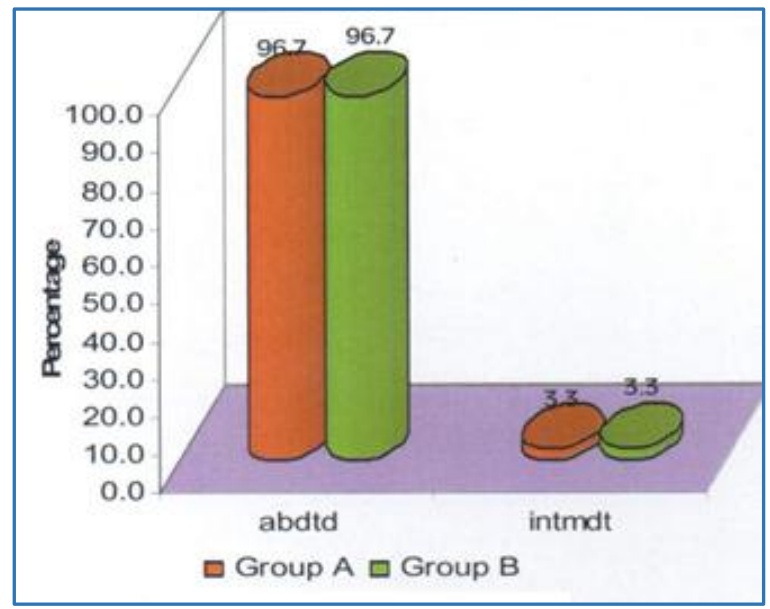

Figure ix. Comparison of sample based on VC position

No significant difference in vocal cord position was noted in both groups.

\begin{tabular}{|c|c|c|c|c|}
\hline \multirow{2}{*}{$\begin{array}{c}\text { Vocal Cord } \\
\text { Movement }\end{array}$} & \multicolumn{2}{|c|}{ Group A } & \multicolumn{2}{c|}{ Group B } \\
\cline { 2 - 5 } & Count & Percent & Count & Percent \\
\hline Nil & 60 & 100.0 & 60 & 100.0 \\
\hline Others & 0 & 0.0 & 0 & 0.0 \\
\hline \multicolumn{4}{|c|}{ Figure x. Comparison of sample } \\
based on Vocal Cord movement \\
\hline
\end{tabular}

Vocal Cord movement was comparable in both groups.

\begin{tabular}{|c|c|c|c|c|}
\hline \multirow{2}{*}{$\begin{array}{c}\text { Limb } \\
\text { Movement }\end{array}$} & \multicolumn{2}{|c|}{ Group A } & \multicolumn{2}{c|}{ Group B } \\
\cline { 2 - 5 } Nil & 60 & 100.0 & 60 & 100.0 \\
\hline Others & 0 & 0.0 & 0 & 0.0 \\
\hline \multicolumn{4}{|c|}{$\begin{array}{c}\text { Figure xi. Comparison of sample } \\
\text { based on limb movement }\end{array}$} \\
\hline
\end{tabular}

None of the patients in either group developed limb movement during laryngoscopy.

\begin{tabular}{|c|c|c|c|c|}
\hline Coughing & \multicolumn{2}{|c|}{ Group A } & \multicolumn{2}{c|}{ Group B } \\
\hline Nil & 60 & 100.0 & 60 & 100.0 \\
\hline Others & 0 & 0.0 & 0 & 0.0 \\
\hline Figure xii. Comparison of sample based on Coughing \\
\hline
\end{tabular}


The ease of intubation was comparable in both groups.

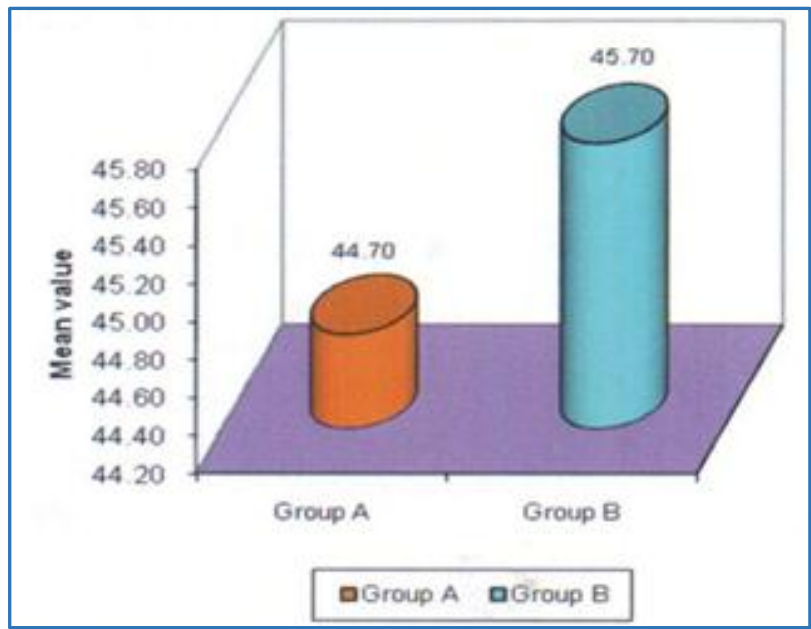

Figure xiii. Comparison of sample based on duration of action

The duration of action of rocuronium was comparable in either group.

Comparison of patients based on the occurrence of adverse effects at the site of injection.

None of the patients in either groups developed adverse effects in the form of oedema, wheal, pain and flare response within 24 hours at the site of injection.

\section{DISCUSSION}

Pain during induction of anaesthesia is distressing and it increases the stress and anxiety among patients just before surgery. Rocuronium is a widely used steroidal neuro muscular blocking agent with an intermediate duration and rapid onset of action. The major disadvantage of Rocuronium is the pain associated with its injection, the cause of which is not clear. With a subparalysing dose, $50-100 \%$ of patients report discomfort. Even after induction of anaesthesia with propofol and thiopental, rocuronium causes hand or limb withdrawal in $85 \%$ of patients suggesting the presence of intense nociception even during anaesthesia. Lui et al reported a child who developed pulmonary aspiration secondary to gastric regurgitation caused by spontaneous movements after the injection of rocuronium.(12) Pain, emotional stress and stimulation during induction of anaesthesia may cause bronchospasm or myocardial ischaemia and the withdrawal movement dislodge the venous catheter or cause injury during induction.

Peripheral nerves are innervated with polymodal nociceptors which mediate the response to the injection of certain anaesthetics that cause pain. Blunk et al concluded that the allogeneic effect of aminosteroidal neuro muscular blocking drugs could be attributed to a direct activation of Cnociceptors. Since the publication of several reports of severe burning pain on injection of rocuronium, various mechanisms responsible for pain on injection have been postulated. The mechanism is still unclear. Lockey and Coleman described a marked discomfort in patients when rocuronium was injected, entirely separate in timing and quality from that caused by propofol,(13) because rocuronium bromide is formulated with sodium acetate, sodium chloride or acetic acid to produce a solution of $\mathrm{pH} 4$, Lockey and Coleman postulated that the low $\mathrm{pH}$ is a possible cause of pain. Indeed, Klement and Amdt found that pain on injection of some drugs are likely to be caused by formulations of extremely unphysiological osmolalities or $\mathrm{pH}$ values. Borgeat and Kwiatkowski speculated that local release of mediators might be the cause of pain.(14)

Mechanism of pain is due to direct activation of Cnociceptor by the osmolality or $\mathrm{pH}$ of the solution or activation by the release of endogenous mediators like histamine kinin and other substances mediating inflammation.(15) Kininogen cascade similar to that associated with propofol may be responsible. Several treatment modalities have been studied in an attempt to reduce the pain on injection of rocuronium, albeit with variable success rates. These include pretreatment with lidocaine, sodium bicarbonate, esmolol,(16) ketamine, opioids, ondansetron, antihistaminics, dexmedetomidine and injection of diluted rocuronium or administering it as an infusion rather than as a bolus injection. The incidence of pain has been reported to be $20 \%$ to $28 \%$ with lidocaine and $10 \%$ to $14 \%$ with sodium bicarbonate.

\section{Pain Pathways}

Pain is conducted along three-neuron pathways that transmit noxious stimuli from the periphery to the cerebral cortex. Primary afferent neurons are located in the dorsal root ganglia, which lie in the vertebral foramina at each spinal cord level. Each neuron has a single axon that bifurcates, sending one end to the peripheral tissues it innervates and the other into the dorsal horn of the spinal cord. In the dorsal horn, the primary afferent neuron synapses with a secondorder neuron whose axons cross the midline and ascend in the contralateral spinothalamic tract to reach the thalamus. Second order neurons synapse in thalamic nuclei with third order neurons, which in turn send projections through the internal capsule and corona radiate to the post central gyrus of the cerebral cortex.

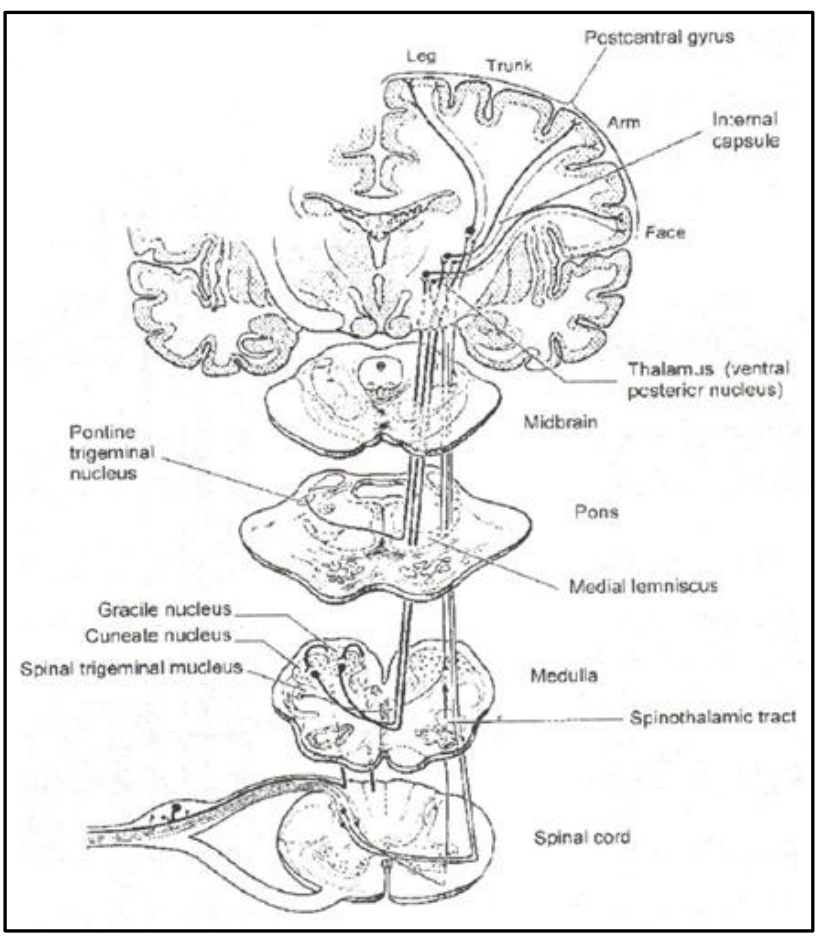

Figure xiv. Pain Pathways 


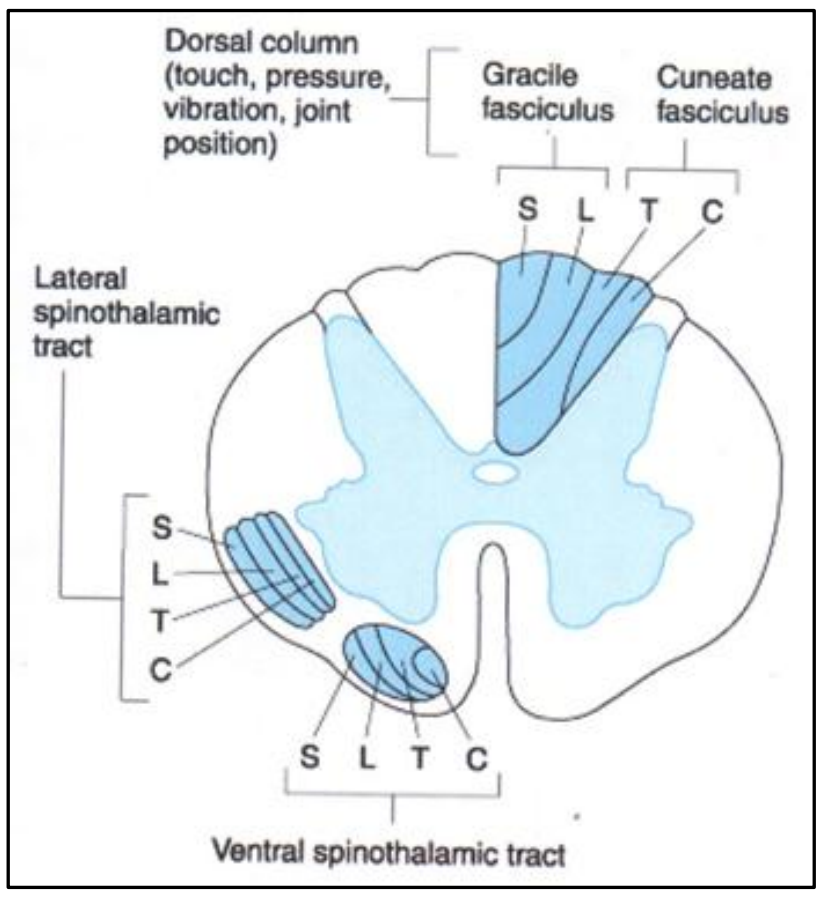

\section{Figure xv. CS of spinal cord showing spinothalamic pathway}

In the present study, patients in both groups were not premedicated in the operation theatre to assess limb withdrawal response to iv rocuronium.

Group A received rocuronium mixed with sodium bicarbonate and group B received rocuronium mixed with lignocaine. Neutralisation of acidic $\mathrm{PH}$ of rocuronium decreased the pain in group A whereas the local anaesthetic action of lignocaine decreased the pain in group B. This study was done to evaluate which group received less pain.

After checking the baseline heart rate, systolic BP and diastolic BP, a sleeping dose of iv thiopentone was given to all patients in either groups followed by iv loading dose of rocuronium. This was to avoid the discomfort associated with the injection of rocuronium. The haemodynamic variables were measured during the period of rocuronium injection and only those patients in either group who perceived pain during injection showed significant changes in heart rate and BP.

After administering rocuronium, a total of $1.5 \mathrm{mg} / \mathrm{kg}$ of lignocaine was given to patients in both groups to attenuate the stress response associated with laryngoscopy and intubation. There was no significant change in the haemodynamic variables during laryngoscopy except for a slight change in the HR in group B which may be explained by the higher baseline HR values in the same group. The ease of intubation was comparable in either group.

The duration of action of rocuronium showed no significant difference in either group. No patients in either group reported any adverse effects at the site of injection after 24 hours.

\section{Justification of the Sample Size}

Even though it is not very large, the sample size used in the present study has been statistically adequate enough to make this study relevant and representative.

\section{CONCLUSION}

After analysing the results of the present study, we find that injection of neutralized rocuronium is more efficacious than lignocaine in reducing the pain and withdrawal movements associated with the injection of rocuronium bromide.

The hemodynamic response associated with injection of a loading dose of rocuronium bromide was more in the lignocaine group than in sodium bicarbonate group while that associated with intubation was comparable in either group. There was no significant change in the duration of action of rocuronium in either groups and the ease of intubation was also comparable between the groups. None of the patients in both groups developed any adverse effects at the injection site within 24 hours.

\section{REFERENCES}

[1] Sasakawa T, Iwasaki H. Does rocuronium displace the position of suxamethonium? Masui 2008;57(7):860-8.

[2] Perry JJ, Lee JS, Sillberg VA, et al. Rocuronium versus succinylcholine for rapid sequence induction intubation. Cochrane Database Systematic Reviews 2008;(2):CD002788.

[3] Schreiber JU, Lysakowski C, Fuchs-Buder T, et al. Prevention of succinylcholine-induced fasciculation and myalgia: a meta-analysis of randomized trials. Anesthesiology 2005;103(4):877-84.

[4] Blunk JA, Seifert F, Schmelz M, et al. Injection pain of rocuronium and vecuronium is evoked by direct activation of nociceptive nerve endings. European Journal of Anaesthesiology 2003;20(3):245-53.

[5] Shevchenko Y, Jocson JC, McRae VA, et al. The use of lidocaine for preventing the withdrawal associated with the injection of rocuronium in children and adolescents. Anesthesia \& Analgesia 1999;88(4):7468.

[6] Chiarella AB, Jolly DT, Huston CM, et al. Comparison of four strategies to reduce the pain associated with intravenous administration of rocuronium. British Journal of Anaesthesia 2003;90(3):377-9.

[7] Lee HJ, Han SJ, Kim $H$, et al. Antihistamine pretreatment to reduce incidence of withdrawal movement after rocuronium injection. Journal of Korean Medical Science 2009;24(5):879-82.

[8] Kim JY, Kim JY, Kim YB, et al. Pretreatment with remifentanil to prevent withdrawal after rocuronium in children. British Journal of Anaesthesia 2007;98(1):120-3.

[9] Han DW, Koo BN, Choi SH, et al. Neutralized rocuronium ( $\mathrm{pH}$ 7.4) before administration prevents injection pain in awake patients: a randomized prospective trial. Journal of Clinical Anesthesia 2007;19(6):418-23.

[10] Liou JT, Hsu JC, Liu FC, et al. Pretreatment with smalldose ketamine reduces withdrawal movements associated with injection of rocuronium in pediatric patients. Anesthesia \& Analgesia 2003;97(5):1294-7.

[11] Memis D, Turan A, Kaya G, et al. Preventing pain on injection of rocuronium: two doses of dexmedetomidine. Canadian Journal Anesthesia 2005;52(4):437-8. 
[12] Lui JT, Huang SJ, Yang CY, et al. Rocuronium-induced generalized spontaneous movements cause pulmonary aspiration. Chang Gung Mededical Journal 2002;25(9):617-20.

[13] Lockey D, Coleman P. Pain during injection of rocuronium bromide. Anaesthesia 1995;50(5):474.

[14] Kwiatkowski D, Borgeat A. Spontaneous movements associated with rocuronium: is pain on injection the cause? European Journal Anaesthesiology 1997;14(Supplement 15):59.
[15] Naguib M, Samarkandi AH, Bakhamees HS, et al. Histamine-release haemodynamic changes produced by rocuronium, vecuronium, mivacurium, atracurium and tubocurarine. British Journal Anaesthesia 1995;75(5):588-92.

[16] Yavascaoglu B, Kaya F, Ozcan B. Esmolol pretreatment reduces the frequency and severity of pain on injection of rocuronium. Journal Clinical Anesthesia 2007;19(6):413-7. 